Special issue of the 3rd International Conference on Computational and Experimental Science and Engineering (ICCESEN 2016)

\title{
Characterization of Nanocrystalline Cu25Mo Electrical Contact Material Synthesized via Ball Milling
}

\author{
S. BIYIK* \\ Karadeniz Technical University, Abdullah Kanca Vocational School, Department of Machinery \\ and Metal Technologies, Trabzon, Turkey
}

\begin{abstract}
In this study, Cu-based Mo-doped composite powder was synthesized by ball milling technique. Elemental powder mixture containing $25 \mathrm{wt} . \%$ Mo was milled in a high-energy planetary-type ball mill to achieve homogeneously mixed composite powder. Characterization of the starting and the milled powders was carried out using scanning electron microscopy and laser diffraction analysis. It was found that particle size of powder had gradually decreased with increasing milling duration. scanning electron microscope pictures, corresponding to the later stages of milling process prove that nanocrystalline powders were obtained after milling duration of $30 \mathrm{~h}$. Prolonged milling durations lead to powder contamination, which is undesirable for contact applications, where the purity is of big importance. Therefore, optimum milling duration was determined to be $30 \mathrm{~h}$.
\end{abstract}

DOI: 10.12693/APhysPolA.132.886

PACS/topics: 81.20.Ev, 84.32.Dd

\section{Introduction}

Electrical contacts are frequently used to make and to break electrical circuits in electromagnetic switches, such as relays and contactors. An electrical arc causes erosion of the contacts by melting and vaporization [1]. Besides, material transfer between contacts can hinder their ability to operate properly. Therefore, materials with various properties should be combined to obtain a novel contact material with superior performance [2].

Copper based materials are used in electrical contacts because of their high electrical and thermal conductivities, low cost, and ease of fabrication. The main drawbacks of these materials are poor resistance to oxidation and corrosion [3]. Forming a composite can compensate for these drawbacks. Hence, different types of Cu-based composite electrical contact materials have been developed to meet the requirements for various applications [4].

Applications involving severe arcing and welding employ contacts made from refractory metals, such as tungsten (W) and molybdenum (Mo), which have high melting and boiling points, and excellent resistance to arcerosion [3]. Composites such as these are made by powder metallurgy (PM) techniques because the individual constituents are immiscible and cannot be made by conventional melt-cast process. Composite materials offer enhanced physical and mechanical properties over many other products [5-10].

To enhance arc-erosion performance of electrical contacts, material parameters, such as composition and homogeneity of the powder mixture, should be considered. This is because the fine and homogeneous dispersion of refractory metals within the matrix enables to obtain

*e-mail: serkanbiyik@ktu.edu.tr contacts superior to the conventional ones [4]. Therefore, conventional PM method is combined with mechanical alloying (MA) technique. Much work has been done towards producing and evaluating the electrical performance of contact materials [11-16]. However, the synthesis and characterization of a nanocrystalline contact material containing refractory metals have not yet been investigated in detail. Therefore, the primary purpose of the present study is to enhance arc-erosion performance via manufacturing a nanocrystalline $\mathrm{Cu}$-based contact material, containing Mo, by ball milling.

\section{Experimental procedures}

Elemental powders of $\mathrm{Cu}$ (average particle size (APS) of $10 \mu \mathrm{m}, 99.9 \%$ purity) and Mo (APS of 3-7 $\mu \mathrm{m}, 99.95 \%$ purity) were used in ball milling experiments. Both powders (Fig. 1) were supplied by Alfa Aesar Corporation.
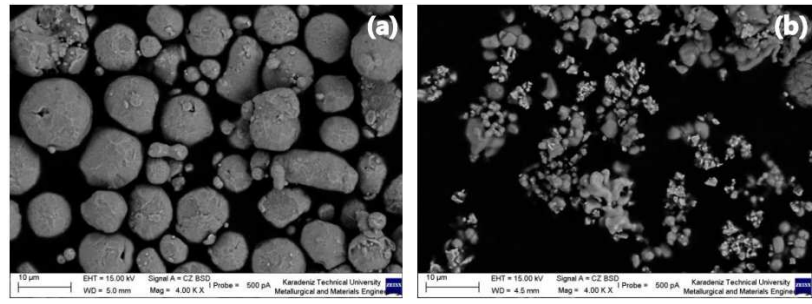

Fig. 1. Morphology of as-received (a) $\mathrm{Cu}$ and (b) Mo powders.

Mo powders (reinforcement) were added to $\mathrm{Cu}$ powders (matrix) in the amount of $25 \mathrm{wt} . \%$. Milling experiments were conducted using a planetary-type ball mill (Retsch PM 100) with a milling speed of $300 \mathrm{rpm}$ and a ball-topowder weight ratio (BPR) of 10:1. After completion of certain number of milling runs, the powder samples were withdrawn from the vial, and then subjected to particle 
size determination by laser diffractometry (Mastersizer 2000, Malvern Instruments). Morphological evolution of the starting and milled powders was carried out using scanning electron microscopy (SEM; Zeiss Evo LS 10).

\section{Results and discussion}

From a morphological point of view, $\mathrm{Cu}$ particles have a spherical shape, whereas Mo particles have an irregular shape (Fig. 1). The APS values of the Cu25Mo powder mixture with respect to milling duration are listed in Table I. The curve in Fig. 2 was plotted using the APS values from this table.

TABLE I

Average particle size of Cu25Mo powder mixture as a function of milling duration $t$.

\begin{tabular}{c|c|c|c|c|c|c|c|c|c|c}
\hline \hline $\begin{array}{c}t \\
{[\mathrm{~h}]}\end{array}$ & 0 & 0.5 & 2 & 4 & 7 & 10 & 15 & 20 & 25 & 30 \\
\hline $\begin{array}{c}d_{50} \\
{[\mu \mathrm{m}]}\end{array}$ & 11.19 & 12.83 & 15.11 & 14.67 & 11.46 & 10.66 & 4.57 & 3.49 & 3.08 & 2.22 \\
\hline
\end{tabular}

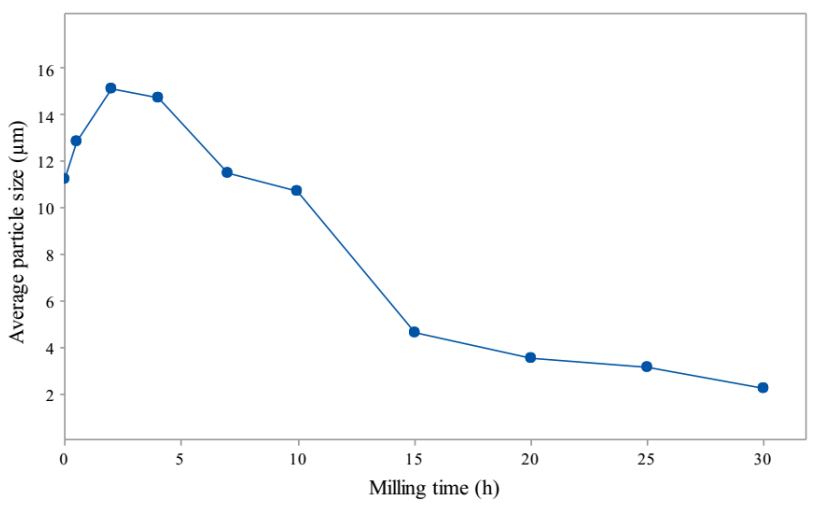

Fig. 2. Particle size variation of Cu25Mo powder mixture as a function of milling duration.

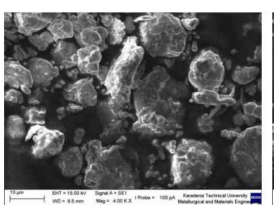

(a)

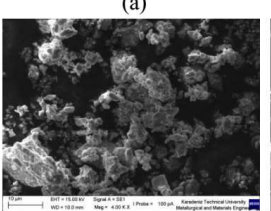

(d)
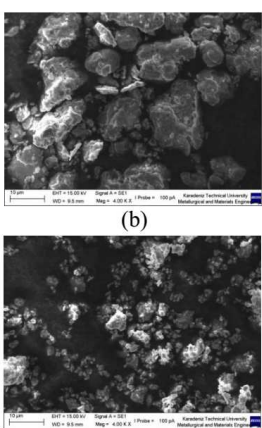

(e)

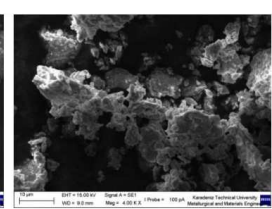

(c)

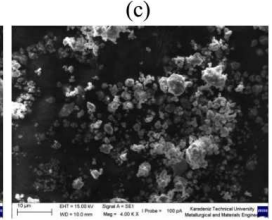

(f)

Fig. 3. Morphology of the Cu25Mo powder mixture after ball milling for (a) 0.5 , (b) 2, (c) 4, (d) 7, (e) 10 and (f) $20 \mathrm{~h}$.

Figure 3 shows the morphological evolution of the powder mixture after milling for $0.5,2,4,7,10$ and $20 \mathrm{~h}$.

The powder particles exhibit significant morphological change with continued milling, and particle size generally decreases with increasing milling time. However, it is apparently seen from Figs. 2 and 3 that, there is no considerable amount of particle size reduction up to milling duration of $7 \mathrm{~h}$. Besides, some fluctuations in particle size were observed especially after the milling duration of 0.5 and $2 \mathrm{~h}$ (Table I). This increment in particle size may be attributed to the increase in cold welding. The powder particles get cold welded to each other due to the heavy plastic deformation they undergo during milling. Consequently, particle size tends to increase in this initial period of milling.

This situation proves that the balance between cold welding and fracturing is not yet achieved. Therefore, the majority of the powder particles exhibit flake morphology with increasing milling duration up to $4 \mathrm{~h}$ (Fig. 3a-c). Fracturing of the cold-welded particles starts after the milling duration of $4 \mathrm{~h}$ (Fig. 3d). The morphology is transformed into flaky plus semi-equiaxed at $7-10 \mathrm{~h}$ (Fig. 3d and e). With continued milling, especially after $10 \mathrm{~h}$, fracturing of the powder particles is dominant over cold welding phenomenon (Fig. 3e and f). These competing events of cold welding (with plastic deformation and agglomeration) and fracturing (size reduction) continue repeatedly throughout the milling period. It should also be emphasized that the improvement in homogeneity emerges after the milling duration of $10 \mathrm{~h}$.

The most effective particle size reduction was obtained in the range that corresponds to milling duration between 10 and $15 \mathrm{~h}$. Particle size is decreased from $10.656 \mu \mathrm{m}$ to $4.569 \mu \mathrm{m}$ in this milling period. It should be also pointed out that $15 \mathrm{~h}$ of milling duration correspond to a critical point where the equilibrium state of milling is almost reached. The rate of decrease in particle size slows down after this critical value. Thus, a very limited amount of particle size reduction $(4.569 \mu \mathrm{m}$ to $3.490 \mu \mathrm{m})$ occurs in the range that corresponds to milling duration between 15 and $20 \mathrm{~h}$. A similar trend is observed during the later stages of ball milling process. Particle size is decreased to $2.215 \mu \mathrm{m}$ after the milling duration of $30 \mathrm{~h}$.
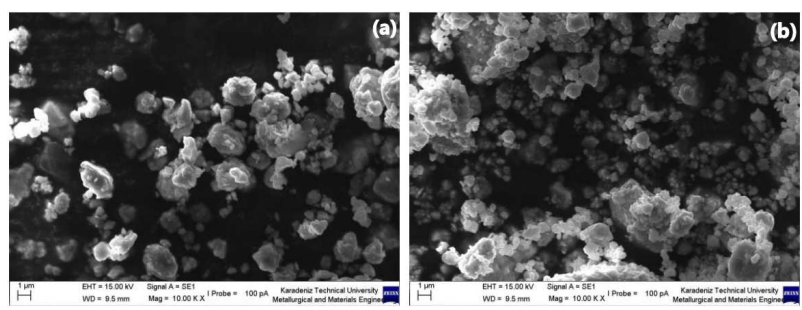

Fig. 4. Morphology of the Cu25Mo powder mixture after ball milling for (a) 20 and (b) $30 \mathrm{~h}$.

Figure 4 shows scanning electron microscope (SEM) images of the $\mathrm{Cu} 25 \mathrm{Mo}$ powder mixture after ball milling for 20 and $30 \mathrm{~h}$. The morphology is transformed from flaky plus semi-equiaxed to semi-equiaxed after the milling duration of $20 \mathrm{~h}$ (Figs. 3f and 4a). Thus, a more 
homogeneous dispersion of Mo reinforcement particles in the $\mathrm{Cu}$ matrix is observed, owing to balance between cold welding and fracturing. With further milling, steady state condition is reached, and equiaxed nanostructured material is synthesized (Fig. 4b).

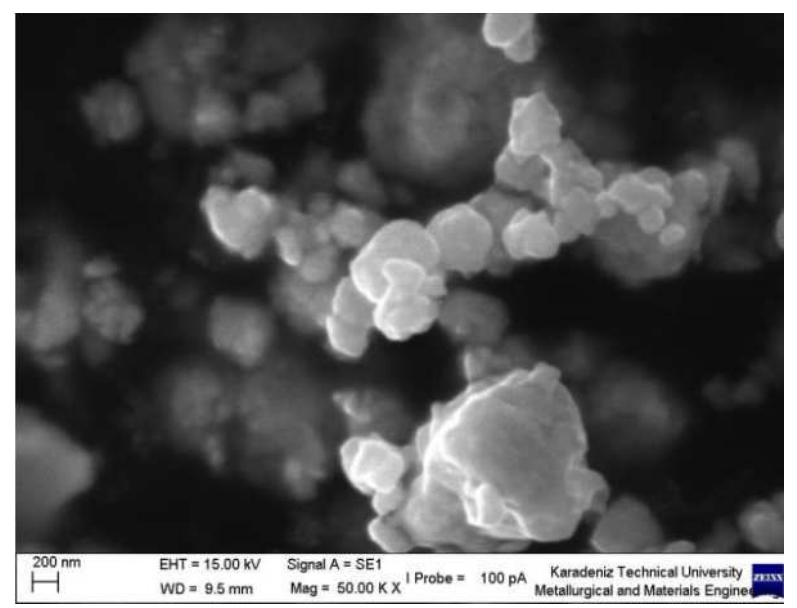

Fig. 5. SEM image of nanocrystalline Cu25Mo composite powder obtained after ball milling for $30 \mathrm{~h}$.

Figure 5 shows the high magnification SEM image of nanocrystalline $\mathrm{Cu} 25 \mathrm{Mo}$ composite powder, obtained after ball milling for $30 \mathrm{~h}$. It is clear from Fig. 5 that nanocrystalline powders have been successfully synthesized. The dispersion of reinforcement phase (Mo) in matrix $(\mathrm{Cu})$ is gradually improved with particle size reduction. Therefore, nanocrystalline powder enables to obtain contacts having superior physical and mechanical properties, as compared to conventional ones, having microcrystalline structure [16]. In addition, nanocrystalline structure provides significant enhancement in arc-erosion performance of electrical contacts, owing to this improvement in properties.

\section{Conclusions}

The nanocrystalline $\mathrm{Cu} 25 \mathrm{Mo}$ composite powder was successfully synthesized by ball milling technique. Particle size generally decreases with increasing milling duration. Some fluctuations in particle size are observed, especially after the milling duration of 0.5 and $2 \mathrm{~h}$. The most effective particle size reduction was obtained in the range that corresponds to milling duration between 10 and $15 \mathrm{~h}$. The minimum particle size $(2.215 \mu \mathrm{m})$ is obtained after the milling duration of $30 \mathrm{~h}$.

The powder morphology was found to be different at different milling durations, namely flaky at $0.5-4 \mathrm{~h}$, flaky plus semi-equiaxed at $7-10 \mathrm{~h}$, semi-equiaxed at $20 \mathrm{~h}$ and equiaxed at $30 \mathrm{~h}$. The optimal milling time is determined as $30 \mathrm{~h}$. Equiaxial morphology is achieved after the milling duration of $30 \mathrm{~h}$. Excessive or prolonged milling durations promote powder contamination, which is undesirable for contact applications, where the purity is of big importance. Since the powder particles become finer with milling time, their surface area increases and consequently the amount of contamination increases. This situation is a major problem in sustaining electrical conductivity, and it should be eliminated or at least minimized. Moreover, the powder yield decreases beyond the optimal milling time. Therefore, the powders were no longer milled beyond $30 \mathrm{~h}$.

Nanocrystalline powders are obtained after the milling duration of $30 \mathrm{~h}$. Nanocrystalline structure provides significant enhancement in arc-erosion performance of electrical contacts, since it improves dispersion of reinforcement phases (Mo) in matrix $(\mathrm{Cu})$, and enables to obtain contacts, having superior physical and mechanical properties, as compared to conventional ones, having microcrystalline structure.

\section{References}

[1] P.G. Slade, Electrical Contacts: Principles and Applications, CRC, Boca Raton 2014.

[2] S. Biyik, F. Arslan, M. Aydin, J. Electronic Mater. 44, 457 (2015).

[3] ASM Handbook, Vol. 7, Powder Metal Technologies and Applications, ASM International Materials Park, Ohio 1998

[4] S. Biyik, M. Aydin, Acta Phys. Pol. A 127, 1255 (2015).

[5] G. Li, H. Cui, J. Chen, X. Fang, W. Feng, J. Liu, J. Alloys Compounds 696, 1228 (2017).

[6] S. Eksi, K. Genel, Acta Phys. Pol. A 128, B-59 (2015).

[7] A. Akkas, A.B. Tugrul, B. Buyuk, A.O. Addemir, M. Marsoglu, B. Agacan, Acta Phys. Pol. A 128, B-176 (2015).

[8] H. Li, X. Wang, X. Guo, X. Yang, S. Liang, Mater. Design 114, 139 (2017).

[9] N. Ozsoy, M. Ozsoy, A. Mimaroglu, Acta Phys. Pol. A 128, B-55 (2015).

[10] M.A. Al-Akhras, S. Saq'an, Z. Ghadieh, Acta Phys. Pol. A 130, 447 (2016).

[11] J. Wang, W. Liu, D. Li, Y. Wang, J. Alloys Compounds 588, 378 (2014).

[12] S. Biyik, M. Aydin, Acta Phys. Pol. A 129, 656 (2016).

[13] H. Li, X. Wang, Y. Liu, X. Guo, Vacuum 135, 55 (2017).

[14] Z. Lin, S. Liu, J. Li, J. Chen, M. Xie, X. Li, M. Zhang, Q. Zhu, D. Huo, X. Sun, Mater. Design 108, 640 (2016).

[15] J. Wang, Y. Kang, C. Wang, J. Alloys Compounds 686, 702 (2016).

[16] V. Cosovic, A. Cosovic, N. Talijan, D. Zivkovic, D. Manasijevic, D. Minic, J. Alloys Compounds 567, 33 (2013). 